\title{
Daño ultraestructural del intestino medio abdominal de Lutzomyia ovallesi (Ortiz) (Diptera: Psychodidae) ocasionado por Leishmania (Leishmania) amazonensis
}

\author{
ELSA NIEVES*, DELSY DÁVILA - VERA** y ERNESTO PALACIOS-PRÜ**
}

\section{ULTRASTRUCTURAL DAMAGE TO THE MIDDLE INTESTINE OF Lutzomyia ovallesi (Ortiz) (DIPTERA: PSYCHODIDAE) CAUSED BY Leishmania (Leishmania) amazonensis}

A study was done in the middle intestine of Lutzomyia ovallesi infected with Leishmania (Leishmania) amzonensis. The females were examined seven days after infection by means of high resolution light microscopy and transmission electron microscopy. Two kinds of epithelial cells, digestive and secretory, were observed in the middle intestine of $\boldsymbol{L}$. ovallesi, in both control insects and in those infected. Results showed changes in the cytoarchitecture of the intestine as a consequence of infection with $\boldsymbol{L} .(\boldsymbol{L}$.$) amazonensis. There was a great increase in the diameter of the intestine, showing signs$ of cellular degeneration, such as partial or total loss of microvilli and the thickening of the basal layer of the whole portion of the intestine. Epithelial cells showed damage in vacuoles and mitochondria, and epithelial waste was observable in the intestine. Cellular damage in the middle intestine of $\boldsymbol{L}$. ovallesi produced by infection with $\boldsymbol{L}$. (L.) amazonensis is perhaps connected with lectin secretion and formation of gel, similar to that of a matrix, in the intestinal lumen. More studies are needed to clarify important aspects of the relationship between Leishmania and the vector.

Key words: Epithelial cells, cellular damage, phlebotomines, relationship Leishmania - vector.

\section{INTRODUCCIÓN}

Lutzomyia ovallesi (Diptera: Psychodidae) se considera una especie antropofílica, que frecuenta el peridomicilio y ha sido señalada como transmisor de Leishmania mexicana en la región centro occidental de Venezuela ${ }^{1-3}$. L. ovallesi también es uno de los principales transmisores de Leishmania en los Andes Venezolanos, donde presenta un amplio rango de distribución y es la segunda especie en abundancia en la zona ${ }^{4,5}$.
El intestino de los flebotominos ha sido estudiado ultraestructuralmente ${ }^{6,7}$, también como modelo de digestión sanguínea ${ }^{8,9}$ y como modelo de la interrelación Leishmania vector ${ }^{10-12}$. Luego de la digestión sanguínea, en el intestino medio abdominal se produce una serie de cambios morfológicos, que dependen de las alteraciones fisiológicas que ocurren durante el proceso de digestión sanguínea, que van desde la formación de la matriz peritrófica y secreción de enzimas digestivas hasta la absorción y transporte de

\footnotetext{
* Laboratorio de Parasitología Experimental, Departamento de Biología, Facultad de Ciencias

** Centro de Microscopía Electrónica, Facultad de Medicina, Universidad de Los Andes.

E-mail: nevelsa@ula.ve
} 
productos digestivos. El epitelio del intestino medio abdominal de L. longipalpis fue investigado por medio de morfometría ultraestructural ${ }^{8}$, antes y durante la digestión sanguínea, siendo los cambios ultraestructurales y morfológicos similares a los descritos para Phlebotomus longipes ${ }^{6}$ y para mosquitos ${ }^{13}$. Otros autores encuentran que los cambios de la estructura de las células epiteliales del intestino medio abdominal de L. intermedia, durante la digestión sanguínea, son semejantes a los descritos para otros dípteros hematófagos 9 . No obstante, poco se sabe de las células epiteliales del intestino medio abdominal de los flebotominos infectados o no ${ }^{14,15}$. En este trabajo estudiamos la morfología de las células epiteliales del intestino medio abdominal de $L$. ovallesi y su relación con $L$. (L.) amazonensis a nivel de microscopía óptica y electrónica.

\section{MATERIAL Y MÉTODOS}

\section{Mantenimiento e infección de Lutzomyia:} Hembras provenientes de una colonia de laboratorio de L. ovallesi, establecida con insectos capturados en El Arenal, Mérida, Venezuela, fueron utilizadas en todos los experimentos y mantenidos en el laboratorio ${ }^{16}$. Hembras de 3 días de edad fueron infectadas por alimentación artificial a través de membrana de pollo, utilizando sangre de ratón mezclada con amastigotes provenientes de lesiones de hamsters experimentalmente infectados con $L$. (L.) amazonensis. Los amastigotes se homogenizaron en tampón salino, $\mathrm{pH} 7,2 \mathrm{a} 4{ }^{\circ} \mathrm{C}$, se centrifugaron a $14.000 \mathrm{rpm}$, utilizando inóculos de $2 \times 10^{7}$ amastigotes $/ \mathrm{ml}^{17}$. Después de la alimentación, las hembras infectadas y las del grupo control no infectados se mantuvieron a $25^{\circ} \mathrm{C}, 80-95 \%$ de humedad relativa, con suplemento azucarado al $50 \%$ de sacarosa ad libitum.

Disección de Lutzomyia: Las hembras fueron sacrificadas 7 días post-infección luego de ser anestesiadas a $4^{\circ} \mathrm{C}$ por $5 \mathrm{~min}$, se colocaron en solución salina $\mathrm{pH} 7,2$ a $4{ }^{\circ} \mathrm{C}$ y se disecaron bajo observación con un microscopio estereoscópico. Se extrajeron los tubos digestivos y se procesaron para el análisis microscópico. Las muestras control se obtuvieron de la misma manera que las anteriores.

Microscopía de luz de alta resolución y microscopía electrónica: Las muestras se fijaron en mezcla 3:3 preparada en tampón cacodilato
$0,1 \mathrm{M}, \mathrm{pH} 6,3$ a $4^{\circ} \mathrm{C}$ durante 24 horas $^{18}$, posteriormente se lavaron tres veces por $10 \mathrm{~min}$ cada vez en tampón cacodilato. Las muestras fueron post-fijadas por 24 horas en tetráoxido de osmio al $1 \%$ preparado en el mismo tampón, se lavaron nuevamente en solución tampón y se deshidrataron en alcohol etílico en concentraciones ascendentes y finalmente, en óxido de propileno puro. Se infiltraron con la resina epoxídica Epon 812 y la inclusión se realizó con esta misma resina, manteniendo las muestras por 48 horas a $60^{\circ} \mathrm{C}$ para su polimerización. La inclusión se hizo orientando las muestras en posición transversal para obtener las secciones para microscopía de luz de alta resolución y microscopía electrónica. Se hicieron secciones finas de $1 \mu \mathrm{m}$ de espesor y secciones ultrafinas entre 60-100 nm. Los cortes de $1 \mu \mathrm{m}$ se colorearon con Azur II y los cortes ultrafinos se contrastaron con acetato de uranilo y citrato de plomo $^{19}$. Los cortes se observaron en un microscopio de luz de alta resolución (Polyvar Reichert-Jung) y un microscopio electrónico de transmisión (Hitachi H-7000).

\section{RESULTADOS}

El sistema digestivo de L. ovallesi, correspondiente al segmento del intestino medio abdominal bajo estudio, se ilustra en la Figura 1. La Figura 2 se muestra un corte transversal del intestino medio abdominal del grupo control, en la que se observa conservada la arquitectura celular de una monocapa de las células epiteliales, que presentan largas microvellosidades que forman un verdadero borde en cepillo, observándose además, la luz intestinal limpia. Todo el tejido intestinal se encuentra cubierto por una cápsula de células planas que rodea tanto a las células epiteliales propiamente dichas, como a las células secretoras que están intercaladas entre las células epiteliales.

En un corte transversal bajo microscopía electrónica, del intestino medio abdominal del grupo control (Figura 3), se aprecian células intestinales que presentan núcleo con material genético en forma de cordón continuo, enrollado sobre sí mismo, o discontinuo. Las células poseen en su citoplasma vesículas secretoras de corazón electrondenso, que se alternan con vesículas de menor diámetro, electrón lúcidas y de aspecto neurotransmisor. En la Figura 4 se muestra una 


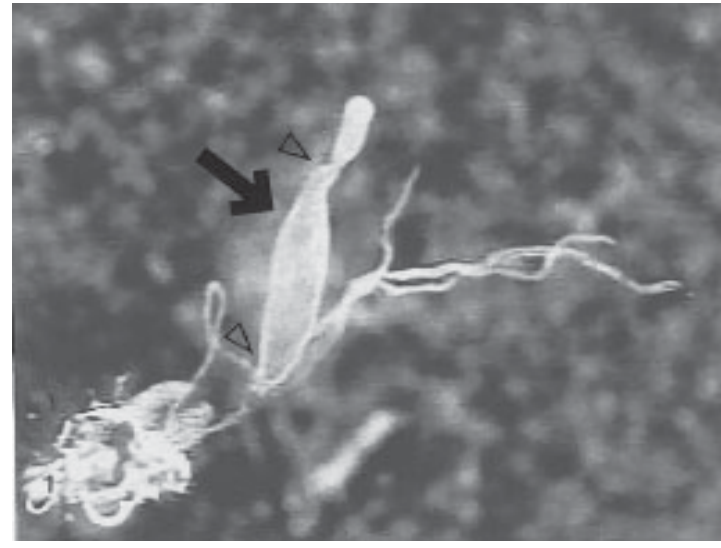

Figura 1. Muestra de sistema digestivo de L. ovallesi suspendido en el líquido de fijación, mantenido a $4^{\circ} \mathrm{C}$. $160 \mathrm{X}$, indicado con una flecha el segmento del intestino medio abdominal.

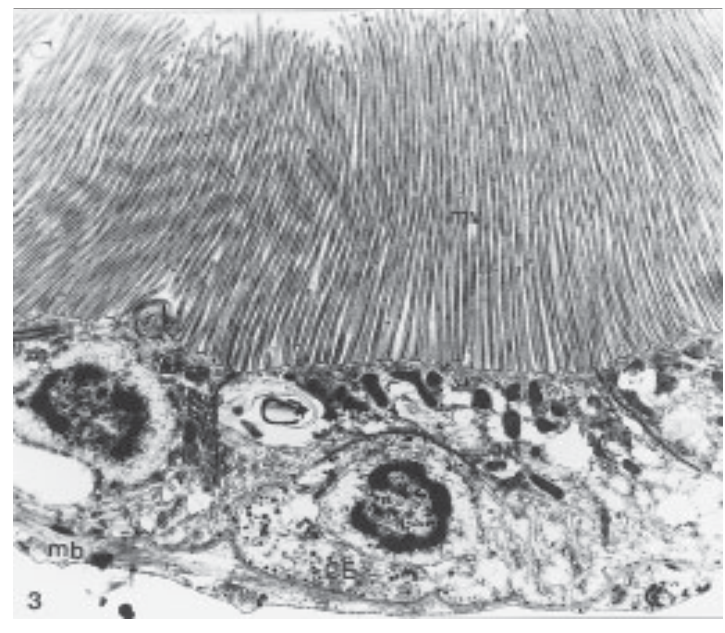

Figura 3. Electronofotografía electrónica a bajo aumento, en la cual pueden verse las largas microvellosidades (mv) emergiendo de la porción apical de las células epiteliales. Entre las células epiteliales se observan las células endocrinas $(\mathrm{CE})$ y rodeando todo el conjunto tisular se aprecia la membrana basal (mb). 16.000 X.

célula vesicular secretora, la cual presenta un conjunto de vesículas electrondensas con dimensiones entre 100 a $200 \mathrm{~nm}$. También se observan grandes masas de material de secreción, cisternas del retículo endoplasmático abundantes y numerosos ribosomas. Estas células poseen un núcleo cuyo material cromosómico se organiza en forma de un grueso cordón, que delimita una región central más electrón densa que el nucleoplasma circundante. La cisterna perinuclear está alejada del cordón cromatínico.

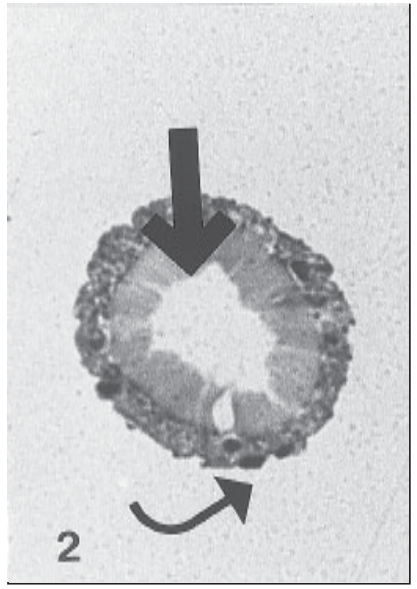

Figura 2. Corte transversal del intestino medio abdominal de L. ovallesi. La luz intestinal se observa reducida por la gruesa capa de microvellosidades que la limita (flecha recta). La pared celular contentiva de las células epiteliales intestinales está compuesta por células de forma cúbica con núcleos ubicados por lo general en posición central. Las células intestinales están rodeadas por células planas, ubicadas en la porción basal del epitelio intestinal (flecha curva) $1.000 \mathrm{X}$.

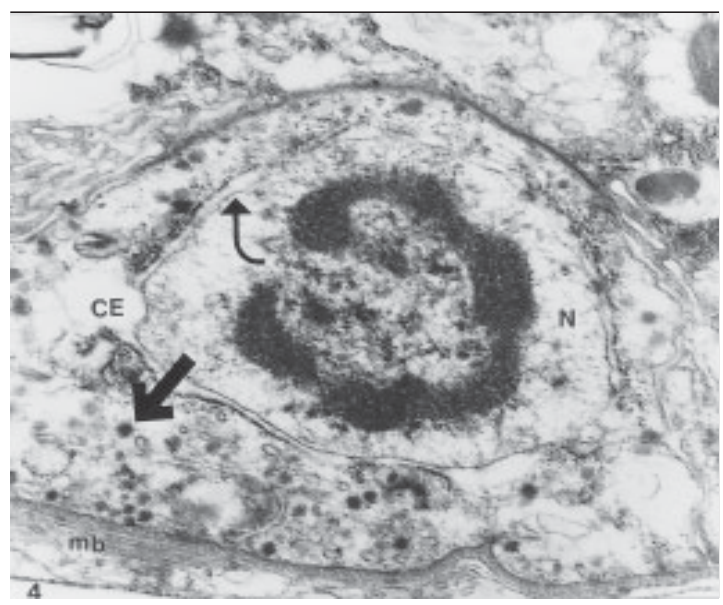

Figura 4. Célula endocrina (CE) en cuyo citoplasma se ven vesículas densas de aspecto neurosecretor (flecha recta) y vesículas claras de menor diámetro y electrón transparentes semejantes a las vesículas neurotransmisoras. El núcleo $(\mathrm{N})$ se encuentra rodeado por una cisterna perinuclear irregular (flecha curva) y la cromatina se organiza centralmente a modo de un cordón. mb, membrana basal. $30.000 \mathrm{X}$.

Las células epiteliales se encuentran adheridas unas a otra, en complejas uniones estrechas, que permite el cierre del espacio intracelular y la formación de redes de canales, lo cual aumenta 
la adherencia entre las células como la que se ilustra en la Figura 5. La membrana basal (Figuras 4 y 5) que rodea al segmento medio del tubo digestivo de Lutzomyia, es de aspecto uniformemente fibrilar en su mayor extensión.

En los segmentos transversales del intestino medio abdominal, proveniente del grupo de Lutzomyia infectadas, se pudo observar grandes cambios citoarquitectónicos de las células que lo componen, se presenta degeneración de las células, con pérdida parcial o total de las microvellosidades, y el interior de éstas se observa muy vacuolado y en franco proceso degenerativo. Se aprecian los parásitos dispersos o en cúmulos en la luz intestinal. También existe una gran distensión del diámetro de la luz intestinal en relación al grupo control. La distensión de este segmento intestinal ocasiona una importante reducción del diámetro celular que obliga a las células digestivas a adoptar configuraciones rectangulares o planas, como se aprecia en las Figuras 6 y 7 . En algunos casos las microvellosidades coalescen y se ven más oscuras, dispuestas en bloques (Figura 6) y en otros casos, desaparecen totalmente. En algunas oportunidades, la reducción de las microvellosidades es más uniforme, sin fragmentarse en bloques, como fue descrito arriba; sin embargo, reducen su longitud y llegan a desaparecer en algunos segmentos (Figura 7). En todos los casos examinados las células intestinales mostraron diversos grados de degeneración citoplasmática.

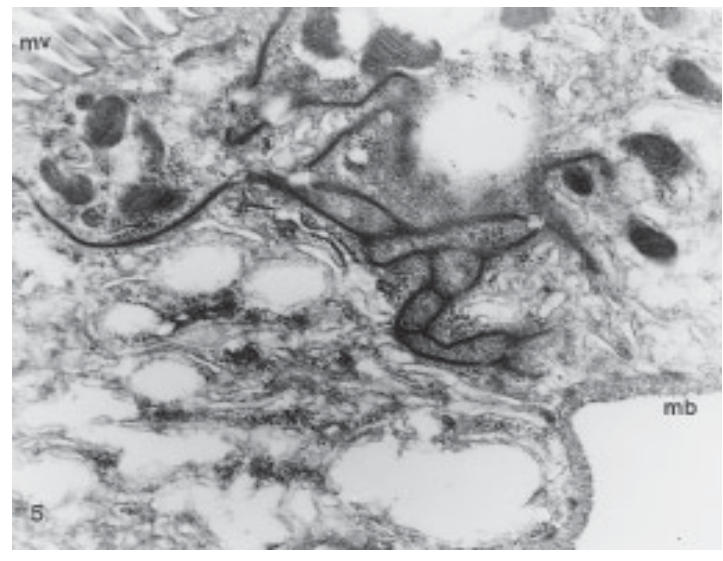

Figura 5. Entre las células epiteliales se encuentran complejos sistemas de uniones estrechas y densas que contribuyen a impermeabilizar el canal intercelular y asegurar la sujeción de las células epiteliales. mv, microvellosidades; mb, membrana basal. 35.000 X.
En el intestino medio abdominal de hembras con 7 días de infección se observaron numerosas Leishmania en proximidad a las microvellosidades, las más cercanas producen desarreglos en las proximidades dístales de las microvellosidades. Se observa microvellosidades más cortas y en la porción más distal se ven curvas. La porción luminal del citoplasma de algunas células muestra degeneración acuosa y en otras, edematización del citoplasma (Figura 8). En los casos en los cuales se conserva mejor el borde de microvellosidades, se apreció claramente su desarreglo y vacuolización. Se observan segmentos celulares con mitocondrias atróficas y degeneración de las vacuolas de las células epiteliales y engrosamiento de la membrana basal de toda la porción del intestino (Figura 9). Las porciones más afectadas del intestino medio abdominal en el citoplasma se observó diversos grados de alteración por edematización y vacuolización (Figuras 8 y 9) o por atrofia (Figura 10). Como indicamos antes, las microvellosidades en algunos segmentos coalescen, se adosan unas a otras y forman acúmulos densos, como los ilustrados en la Figura 10. En la luz intestinal se observan desechos epiteliales. La membrana basal se apreció, en la mayoría de los casos, engrosada y con sus elementos microfibrilares organizados en capas.

En los parásitos presentes en el interior del segmento medio intestinal de los flebotominos infectados mostraron, en líneas generales, sus

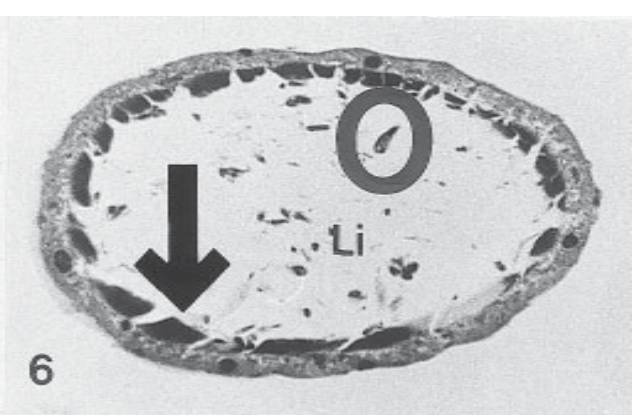

Figura 6. Corte transversal del intestino medio abdominal de L. ovallesi infectada con L. amazonensis. Este segmento intestinal se encuentra distendido en el eje horizontal del plano de corte y en la luz intestinal se observa la presencia de parasitos (círculos) y restos de glóbulos rojos. La flecha muestra la condensación y separación en bloque de las microvellosidades de las células intestinales. Li, luz intestinal. 1.000 X. 


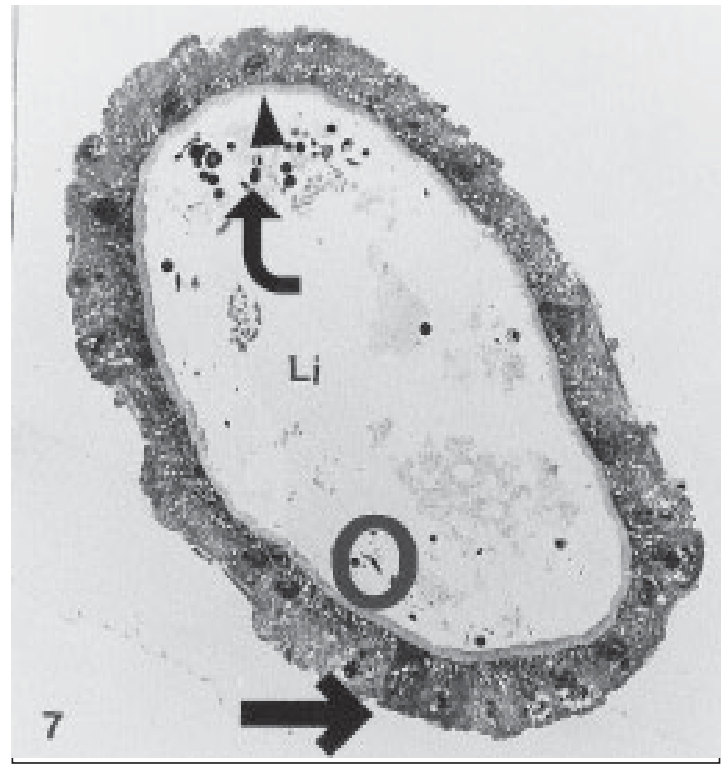

Figura 7. Corte transversal del intestino medio abdominal de L. ovallesi infectada con L. amazonensis en el cual se aprecia una importante reducción de las microve-llosidades hasta alcanzar su extinción (flecha corta). En el interior de la luz intestinal (Li) se ven glóbulos rojos (flecha curva) y Leishmanias (círculo). Nótese la degeneración vacuolar de las células epiteliales alternando con células atróficas (flecha larga). $700 \mathrm{X}$

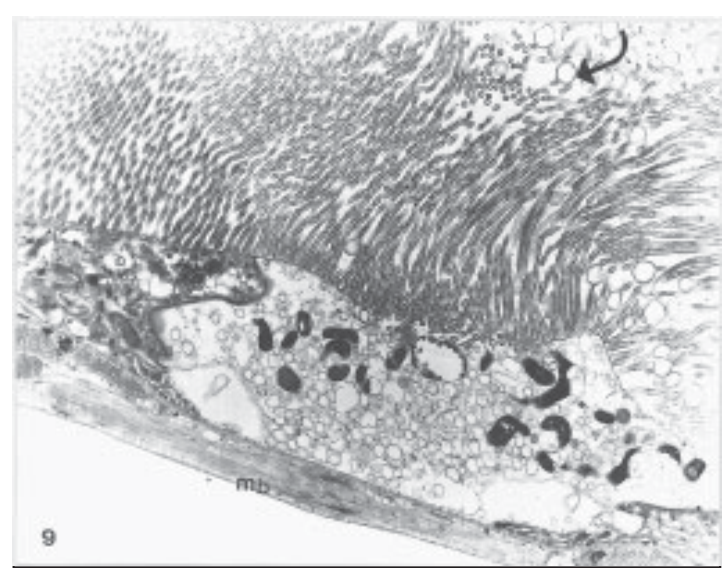

Figura 9. Muestra un grado mayor de alteración de las microvellosidades con vacuolización de las mismas (flecha curva) y existencia de alternancia de células vacuolizadas conteniendo mitocondrias atróficas y células atróficas en todo su contenido (asterisco) mb, membrana basal. 16.000 $\mathrm{X}$.

características ultraestructurales, aun cuando es necesario destacar que en la mayoría de ellas existe una abundante población de vacuolas digestivas claras y vesículas lipídicas, que

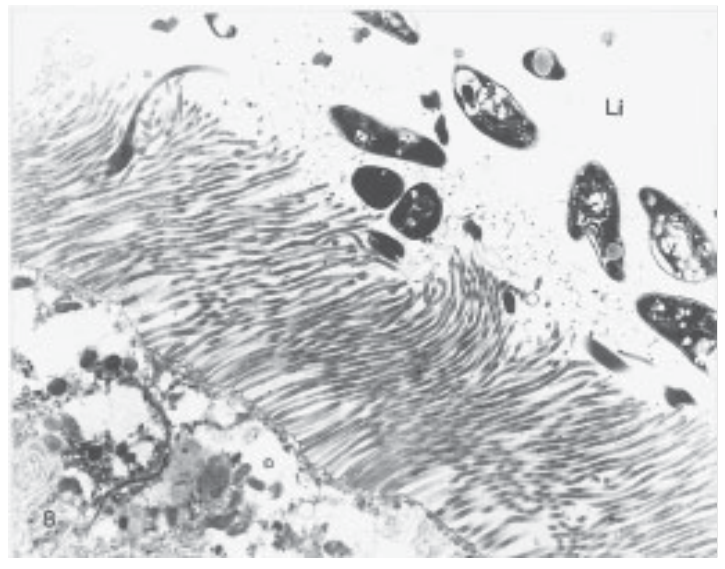

Figura 8. Electronofotografía del intestino medio abdominal de L. ovallesi infectada con L. amazonensis, en el cual se aprecian abundantes cuerpos parasitarios y alteraciones de las microvellosidades, así como edematización del citoplasma de las células intestinales (asterisco). Li, luz intestinal. 16.000 X.

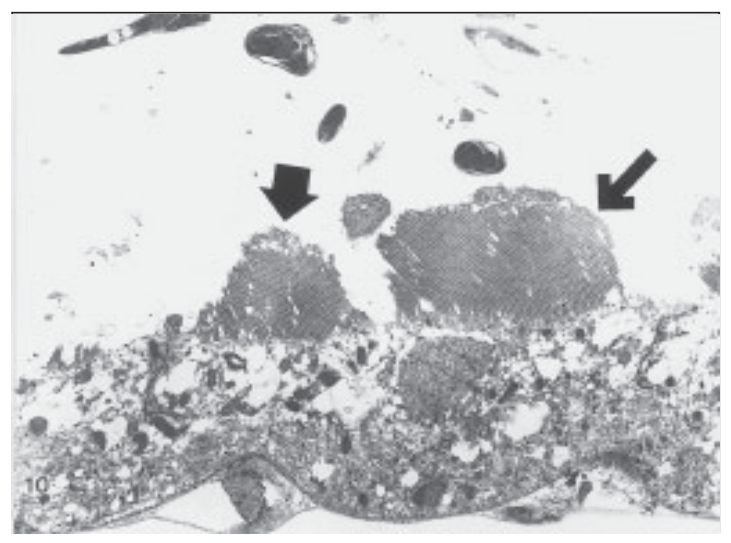

Figura 10. Células epiteliales del intestino medio abdominal de L. ovallesi infectada con L. amazonensis, mostrando claras evidencias de degeneración citoplasmática y coalescencia o empaquetamiento de las microvellosidades (flechas). 12.000 X.

producen deformaciones en el citoplasma, además se observan vesículas y vacuolas que han descargado el líquido en su interior como se aprecia en la Figura 11.

\section{DISCUSIÓN}

Se ha descrito que el epitelio del intestino medio abdominal de los flebotominos, tal como ocurre en otros insectos hematófagos, está formado por una monocapa de tres tipos de células; a saber, digestivas dominantes, degenerativas en menos cantidad que las 


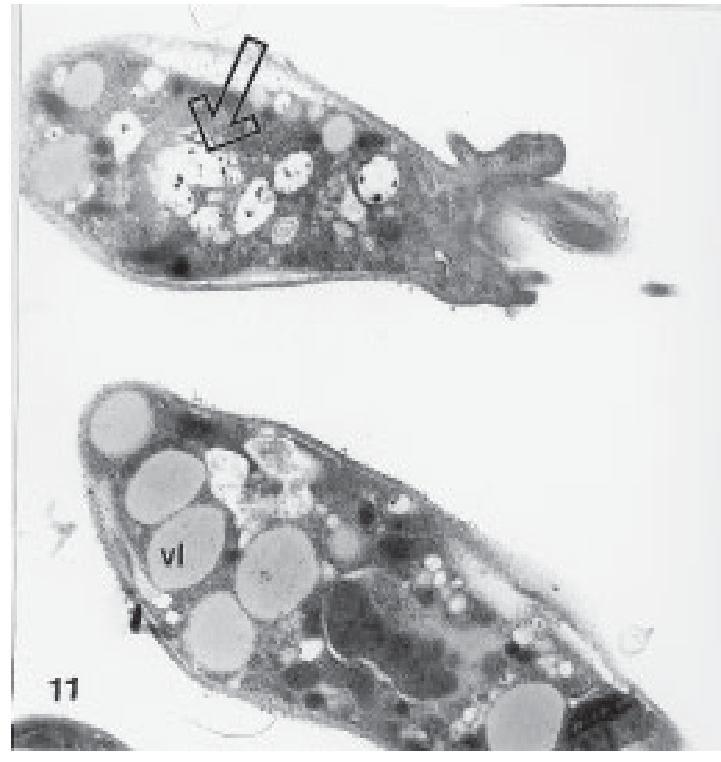

Figura 11. Leishmania en el intestino medio abdominal de L. ovallesi, conteniendo abundantes vacuolas digestivas claras (flecha) y abundantes vacuolas lipídicas (vl). 30.000 $\mathrm{X}$.

anteriores y muy pocas células endocrinas. Las células del epitelio intestinal abdominal se encuentran sobre una lámina basal estrecha y en su superficie apical se encuentran cubiertas por microvellosidades de cerca de $1 \mu \mathrm{m}$ de longitud que forman una densa capa ${ }^{6,8,9,20}$. Las células epiteliales del intestino medio abdominal de $L$. ovallesi, después de 92 horas de la digestión sanguínea, tanto en los controles como en los infectados, presentaron dos tipos morfológicos: una célula secretora y una digestiva. La célula secretora, similar a la descrita como célula endocrina en el intestino medio abdominal de mosquitos adultos ${ }^{21}$, presentó abundantes gránulos de secreción de $60-120$ nm, semejantes a los descritos en el epitelio gastrointestinal de vertebrados. Estas células endocrinas se observan raramente en Nematocera; en los flebotominos se describen por primera vez dos tipos de células endocrinas en un estudio con L. longipalpis, siendo observadas después de 6 horas de la ingesta sanguínea, una de estas células se ubica adyacente a la membrana basal y la otra, más cercana al lumen intestinal. Tal vez los productos secretados por las células endocrinas son estimulados por la ingesta sanguínea ${ }^{20}$ y los mismos podrían estar relacionados con hormonas para el desarrollo de la ovogénesis. Por otra parte, la secreción podría estar relacionada con la secreción de aglutininas semejantes a lectinas, relacionadas con la defensa del insecto. Varios estudios han identificado componentes semejantes a lectinas en el intestino de los flebotominos ${ }^{22-24}$.

En el presente estudio L. ovallesi presentó alteraciones en la citoarquitectura celular producto de la infección con L. (L.) amazonensis. Las células epiteliales presentaron degeneración de vacuolas y mitocondrias. Los resultados del presente trabajo muestran además, que en las porciones más afectadas del intestino medio abdominal, se encuentran células totalmente degeneradas con desaparición segmentaria de las microvellosidades y en la luz intestinal presencia de desechos epiteliales. La pared intestinal por la misma distensión o quizás por la pérdida de células, se ve muy delgada. Es necesario destacar que se producen diferentes grados de distensión del segmento medio del intestino, lo cual puede generarse por efectos mecánicos iniciales y posteriormente, por los productos de secreción del propio parásito. Las largas microvellosidades que poseen las células intestinales o digestivas, sufren tres tipos de alteraciones fundamentales: en algunos segmentos se empaquetan y se reduce el espacio entre ellas, en otros casos éstas desaparecen y en las regiones menos afectadas se reducen de tamaño, se desarreglan y se vacuolizan.

Las células epiteliales del tubo digestivo sufren dos procesos degenerativos. Uno por atrofia o condensación citoplásmica y otro por degeneración vacuolar del sistema de citomembranas. Por su parte, los parásitos también se ven ultraestructuralmente afectados, apareciendo numerosas Leishmania atróficas y otras con abundantes vacuolas digestivas vacías y con grandes vesículas lipídicas.

Además, nuestros resultados en L. ovallesi infectada con $L$. (L.) amazonensis, muestran que las células epiteliales se encuentran adheridas unas a otras, lo cual produce el cierre del espacio intercelular y como consecuencia, forman redes de canales intercelulares que aumentan la adherencia entre las células. En futuros estudios valdría la pena investigar la elasticidad y permeabilidad de estas uniones en diferentes condiciones. Hay evidencias que L. infantum y L. mayor reducen la longevidad y fecundidad de $P h$. papatasi y $P h$. langeroni $i^{25}$. También se ha reportado un efecto nocivo de Leishmania a nivel de la válvula esofágica, producto de la secreción 
de quitinasa por parte del parásito 26,27 .

Por otro lado, el daño celular producido en el intestino medio abdominal de $L$. ovallesi por la infección con $L$. (L.) amazonensis, tal vez tenga relación con la formación del gel semejante a una matriz en el lumen, reportado en varios modelos Leishmania/vector de desarrollo peripiláricos y suprapiláricos, en los cuales se detectó la presencia de una estructura fibrilar, semejante a un gel, en el lumen del intestino medio abdominal ${ }^{28-}$ ${ }^{33}$. Otros estudios muestran que promastigotes de $L$. mexicana y $L$. mayor son capaces de secretar proteofosfoglicano en forma de un gel en los flebotominos, que se observa ultraestructuralmente como una estructura amorfa y fibrilar, y está compuesta principalmente por carbohidratos, con escaso contenido proteico ${ }^{29,34,35}$. En el presente trabajo la sustancia semejante a un gel sólo se formó en los intestinos de L. ovallesi infectados con L. (L.) amazonensis y tal vez se genera por el daño causado por las secreciones de los parásitos en las células epiteliales del intestino, lo cual permite su desplazamiento hacia el gradiente de carbohidrato en dirección al intestino medio torácico, donde al parecer también causa un efecto $\operatorname{similar}^{36}$. Es necesario continuar los estudios para dilucidar aspectos de la interrelación Leishmanial vector. Por todo lo antes descrito podemos afirmar que el tránsito de la Leishmania por el tubo digestivo de Lutzomyia, no es tan inocuo, sino que por el contrario acarrea una serie de alteraciones citológicas, muy pocas de las cuales parecen ser transitorias.

\section{RESUMEN}

Se estudió el intestino medio abdominal de Lutzomyia ovallesi infectada con Leishmania (Leishmania) amazonensis. Las hembras se observaron a los siete días post- infección, utilizando microscopía de luz de alta resolución y microscopía electrónica de transmisión. Se distinguieron dos tipos de células epiteliales, células digestivas y células secretoras, en el intestino medio abdominal de L. ovallesi, tanto en los insectos controles como en flebotominos infectados. Los resultados muestran además, que L. ovallesi presentó alteraciones en la citoarquitectura celular del intestino medio abdominal producto de la infección con $L$. (L.) amazonensis, observándose gran distensión del diámetro de la luz intestinal, degeneración de sus células, pérdida parcial o total de las microvellosidades y engrosamiento de la capa basal de toda la porción del intestino. Las células epiteliales presentaron degeneración vacuolar y mitocondrial y en la luz intestinal se observaron desechos epiteliales. El daño celular observado en el intestino medio abdominal de $L$. ovallesi, pueden tener relación con la secreción de lectinas y con la formación del gel observado, semejante a una matriz, en el lumen del intestino. Es necesario continuar los estudios para dilucidar aspectos importantes de la interrelación Leishmania-vector.

\section{REFERENCIAS}

1.- BONFANTE-GARRIDO R, URDANETA R, URDANETA I, ALVARADO J. Natural infection of Lutzomyia ovallesi (Diptera: Psychodidae) with leishmaniasis in Duaca, Lara State, Venezuela. Trans R Soc Trop Med Hyg 1991; 85: 61-2.

2.- BONFANTE-GARRIDO R, SPINETTI H, CUPILLO E et al. Lutzomyia ovallesi (Diptera: Psychodidae) as a vector of cutaneous leishmaniasis in Venezuela. Parassitologia 1991; 33: 99-104.

3.- FELICIANGELI M D, RODRÍGUEZ N, BRAVO A, et al. Vectors of cutaneous leishmaniasis in northcentral Venezuela. Med Vet Entomol 1994; 8: 317 24.

4.- AÑEZ N, CAZORLA D, NIEVES E, et al. Epidemiología de la leishmaniasis tegumentaria en Mérida, Venezuela. I. Diversidad y dispersión de especies flebotominas en tres pisos altitudinales y su posible rol en la transmisión de la enfermedad. Mem Inst Oswaldo Cruz 1988; 83: 455-63.

5.- AÑEZ N, CAZORLA, D, NIEVES E. Registro de especies de flebótomos en focos endémicos para leishmaniasis en el Estado Mérida, Venezuela. Bol Dir Mal San Amb 1989; 29: 12-34.

6.- GEMETCHU T. The morphology and fine structure of the midgut and peritrophic membrane of the adult female, Phlebotomus longipes Parrot and Martin (Diptera: Psychodidae). Ann Trop Med Parasitol 1974; 68: 111-24.

7.- WALTERS L L, IRONS K P, GUZMAN H, TESH R B. Peritrophic envelopes of Lutzomyia spinicrassa (Diptera:Psychodidae). J Med Entomol 1995; 32: 711 25.

8.- RUDIN W, HECKER H. Functional morphology of the midgut of a sandfly as compared to other hematophagous nematocera. Tissue Cell 1982; 14: 751-8.

9.- ANDRADE-COÊLHO C, SANTOS-MALLET J, SOUZA N A et al. Ultrastructural features of the midgut epithelium of females Lutzomyia intermedia (Luz \& Neiva, 1912) (Diptera: Psychodidae: Phlebotominae). Mem Inst Oswaldo Cruz 2001; 96: 1141-51.

10.- KILLICK-KENDRICK R, MOLYNEUX D H, ASHFORD R W. Leishmania in phlebotomid sandflies I. Modifications of the flagellum associated with attachment to the mid-gut and esophageal valve of 
the sandfly. Proc R Soc Lond Biol Sci 1974; 187: 40919.

11.- WALTERS L L, IRONS K P, MODI G B, TESH R B. Refractory barriers in the sandfly Phlebotomus papatasi (Diptera: Psychodidae) to infection with Leishmania panamensis. Am J Trop Med Hyg 1992; 46: 211-28.

12.- WALTERS L L, IRONS K P, CHAPLIN G, TESH R B. Life cycle of Leishmania major (Kinetoplastida, Trypanosomatidae) in the Neotropical sand fly Lutzomyia longipalpis (Diptera:Psychodidae). J Med Entomol 1993; 30: 699-718.

13.- HECKER H. Structure and function of midgut epithelial cells in Culicidae mosquitoes (Insecta: Diptera). Cell Tissue Res 1977; 184: 321-41.

14.- WEAVER S C, SCOTT T W. Ultrastructural changes in the abdominal midgut of the mosquito, Culiseta melanura, during the gonotrophic cycle. Tissue Cell 1990; 22: 895-909.

15.- ZIELER H, GARON C F, FISCHER E R, SHAHABUDDIN M. A tubular network associated with the brush-border surface of the Aedes aegypti midgut: implications for pathogen transmission by mosquitoes. J Exp Biol 2000; 38: 749-52.

16.- NIEVES E. Problemas de colonización de especies flebotominas bajo condiciones de laboratorio, con especial referencia a Lutzomyia youngi, Lutzomyia ovallesi y Lutzomyia migonei. Trabajo de Ascenso. Merida -Venezuela: Universidad de Los Andes. 1995; $113 \mathrm{p}$.

17.- NIEVES E, PIMENTA F P P. Development of Leishmania (Viannia) braziliensis and Leishmania (Leishmania) amazonensis in the Sand fly Lutzomyia migonei (Diptera:Psychodidae). J Med Entomol 2000; 37: 134-40.

18.- PALACIOS-PRÜ E L, MENDOZA-BRICEÑO R V. An unusual relationship between glial cells and neuronal dendrites in olfactory bulbs of Desmodus rotundus. Brain Research 1972; 36: 204-8.

19.- PALACIOS-PRÜ E L, PALACIOS L, MENDOZABRICEÑO R V. Synaptogenetic mechanisms during chick cerebellar cortex development. J Submicroscopic Cytol 1981; 3: 145-67.

20.- LEITE A C R, EVANGELISTA L G. Ultrastructure of endocrine cells from the abdominal midgut epithelium of Lutzomyia longipalpis (Diptera:Psychodidae). J Med Entomol 2001; 38: 749-52.

21.- BROWN M R, RAIKHEL A S, LEA A O. Ultrastructure of midgut endocrine cells in the adult mosquito, Aedes aegypti. Tissue Cell 1985; 17: 709-21.

22.- WALLBANKS K R, INGRAM R A, MOLYNEUX D $\mathrm{H}$. The agglutination of erythocytes and Leishmania parasites by sandfly gut extracts: evidence for lectin activity. Trop Med Parasitol 1986; 37: 409-13.

23.- VOLF P, KILLICK-KENDRICK R. Post-engorgement dynamics of haemagglutination activity in the midgut of phlebotomine sandflies. Med Vet Entomol 1996; 10: $247-50$.

24.- SVOBODOVA M, VOLF P, KILLICK-KENDRICK R. Agglutination of Leishmania promastigotes by midgut lectins from various species of phlebotomine sandflies. Ann Trop Med Parasitol 1996; 90: 329-36.

25.- SCHLEIN Y, JACOBSON R L, SHLOMAI J. Chitinase secreted by Leishmania functions in the sandfly vector. Pro R Soc Lond B 1991; 245: 121-6.

26.- SCHLEIN Y, JACOBSON R L, MESSER G. Leishmania infections damage the feeding mechanism of the sandfly vector and implement parasite transmission by bite. Proceedings Nat Acad Scien USA 1992; 89: 9944-8.

27.- EL SAWAE B M, EL SATTAR S A, SHEHATA M G, et al. Reduced longevity and fecundity in Leishmaniainfected sand flies. Am J Trop Med Hyg 1994; 51: 767-70.

28.- KILLICK-KENDRICK R, MOLYNEUX D H, LEANEY A J, RIOUX A J. Aspects of the life-cycle of Leishmania in the sandfly. Proceedings Second European Multicolloquy of Parasitol Trogir 1975; 8995.

29.- WALTERS L L, MODI G B, TESH R B, BURRAGE T. Host-parasite relationship of Leishmania mexicana mexicana and Lutzomyia abonnenci (Diptera: Psychodidae). Am J Trop Med Hyg 1987; 36: $294-$ 314.

30.- WALTERS L L, CHAPLIN G L, MODI G B, TESH R B. Ultrastructural biology of Leishmania (Viannia) panamensis (=Leishmania braziliensis panamensis) in Lutzomyia gomesi (Diptera:Psychodidae): a natural host-parasite association. Am J Trop Med Hyg 1989; 40: 19-39.

31.- LAWYER P G, YOUNG D G, BUTLER J F, AKIN D E. Development of Leishmania mexicana in Lutzomyia diabolica and Lutzomyia shannoni (Diptera: Psychodidae) J Med Entomol 1987; 24: 347-55.

32.- LAWYER P G, NGUMBI P M, ANJILI C O et al. Development of Leishmania major in Phlebotomus duboscqi and Sergentomyia schwetzi (Diptera: Pschodidae). Am J Trop Med Hyg 1990; 43: 31-43.

33.- WALTERS L L. Leishmania differentiation in natural and unnatural sandfly hosts. J Euk Microbiol 1993; 40: 196-206.

34.- STIERHOF Y D, BATES P A, JACOBSON R L et al. Filamentous proteophosphoglycan secreted by Leishmania promastigotes forms gel-like treedimensional networks that obstruct the digestive tract of infected sandfly vectors. Eur J Cell Biol 1999; 78: 675-89.

35.- ROGERS M E, CHANCE M L, BATES P A. The role of promastigotes secretory gel in the origin and transmission of the infective stage of Leishmania mexicana by the sandfly Lutzomyia longipalpis. Parasitol 2002; 124: 495-507.

36.- MOLYNEUX D H, RYAN L, LAINSON R, SHAW J J. The Leishmania-sandfly interface. In: Leishmania. Taxonomie et phylogenese. Applications écoépidémiologiques. Coll Int CNRS IMEE Montpellier 1986; 311-24.

Agradecimientos: A los Brs. Neudo Buelvas, Carlos Nasr, Alba Rivas y a los Técnicos Carlos Araque, Maritza Rondón y José Ramírez. Financiamiento: Fonacit, Proyecto: S12000000818 FONACIT y C-1082-01-03-C CDCHT-ULA. Correspondencia: Dra. Elsa Nieves Laboratorio de Parasitología Experimental Departamento de Biología. Facultad de Ciencias.Universidad de Los Andes La Hechicera, Mérida- Edo-Mérida 5101. Venezuela.

Telf: 0274 2712565- FAX: 02742401286 